\title{
Pengaruh Kualitas Layanan Akademik Terhadap Loyalitas Mahasiswa
}

\author{
Eva Zulfa'), Agus Ramdani ${ }^{2)}$, Baehaqi Baehaqi ${ }^{3)}$ \\ 1,2,3 Magister Administrasi Pendidikan \\ email: evazulfa08@gmail.com
}

\begin{abstract}
A good university needs to be balanced with good quality academic services. This study aims to determine the effect of academic service quality $(X)$ on Student Loyalty $(Y)$. This study is an ex-post facto study with 40 student respondents as a sample determined based on purposive sampling technique in determining the sample. The instrument used in this study was a questionnaire with a Likert scale. Linear regression is used to test the hypothesis of the strength of the influence between the independent variables and the dependent variable. The results showed that there was an effect of academic service quality $(X)$ on student loyalty $(Y)$ by $50.0 \%$. These findings indicate that: the quality of academic services $(X)$ has an influence on student loyalty $(Y)$.
\end{abstract}

Keywords: Quality of Academic Service, Ex-post facto, Student Loyalty

Abstrak: Perguruan Tinggi yang baik perlu diimbangi dengan kualitas layanan akademik yang baik. Penelitian ini bertujuan untuk mengetahui pengaruh kualitas layanan akademik (X) terhadap Loyalitas Mahasiswa (Y).Penelitian ini merupakan penelitian ex-post facto dengan 40 responden mahasiswa sebagai sampel yang ditentukan berdasarkan teknik Purposive Sampling dalam penentuan sampel. Instrumen yang digunakan dalam penelitian ini adalah kuesioner dengan skala likert. Regresi linier digunakan untuk menguji hipotesis kuatnya pengaruh antar variabel bebas dengan variabel terikat. Hasil penelitian menunjukkan bahwa ada pengaruh kualitas layanan akademik (X) terhadap loyalitas mahasiswa (Y) sebesar 50,0 \%. Temuan tersebut menunjukkan bahwa: kualitas layanan akademik (X) memiliki pengaruh terhadap loyalitas mahasiswa (Y).

Kata Kunci: Kualitas Layanan Akademik, Ex-post facto, Loyalitas Mahasiswa.

\section{PENDAHULUAN}

Penyelenggaraan pendidikan melalui pendidikan tinggi merupakan salah satu indikator kesadaran masyarakat yang tinggi akan manfaat pendidikan (Annamdevula \& Bellamkonda, 2016). Namun untuk mempersiapkan pendidikan yang berkualitas merupakan tantangan utama di Indonesia. Banyak hal yang perlu diperhatikan untuk meningkatkan kualitas layanan pendidikan bagi peserta didik (Manik \& Sidharta, 2017).

Data dari Dirjen Dikti menunjukkan banyaknya perguruan tinggi hal ini menandakan adanya persaingan antar perguruan tinggi swasta untuk memenangkan persaingan. Persaingan yang tinggi ini membutuhkan pengetahuan dan pemasaran yang baikstrategi dari seluruh perguruan tinggi untuk menjaring calon mahasiswa dari berbagai SMA di Indonesia (Gunawan \& Wahyuni, 2019). Minat calon mahasiswa untuk memilih Perguruan Tinggi sangat dipengaruhi oleh persepsi mereka terhadap perguruan tinggi.

Perguruan Tinggi yang bagus perlu diimbangi dengan kualitas layanan akademik yang baik (Martínez-Argüelles \& Batalla-Busquets, 2016). Dalam menghadapi persaingan antar perguruan tinggi swasta diperlukan strategi untuk memahami kebutuhan dan keinginan mahasiswa (Fares \& Kachkar, 2013). Untuk memenuhi kebutuhan dan keinginan masyarakat dalam memenuhi pendidikan khususnya pendidikan perguruan tinggi 
maka perguruan tinggi perlu mengetahui kebutuhan dan keinginan masyarakat akan pendidikan (Annamdevula \& Bellamkonda, 2016). Pemilihan perguruan tinggi tidak lepas dari unsur layanan yang ditawarkan dan kepuasan mahasiswa.

Mahasiswa memilih Universitas yang sudah mereka kenal dan memiliki citra yang baik. Kotler \& Keller (2015) menyatakan bahwa sikap dan tindakan seseorang terhadap suatu objek sangat ditentukan oleh keyakinannya terhadap citra objek tersebut. Salah satu cara untuk memenangkan persaingan ini adalah dengan memberikan layanan akademik yang berkualitas sehingga dapat memberikan kepuasan kepada mahasiswa dalam mengenyam pendidikan di perguruan tinggi (Imsanova, 2019).

Universitas Nahdlatul Wathan (UNW) Mataram hadir sebagai jawaban atas permintaan kebutuhan masyarakat khususnya warga Nahdlatul Wathan dan masyarakat Nusa Tenggara Barat pada umumnya. Perkembangan UNW Mataram, khususnya Fakultas Ilmu Kesehatan terus menunjukkan perkembangannya dari tahun ke tahun. Selanjutnya, trend perkembangan mahasiswa kurun empat tahun terakhir pada Fakultas Ilmu Kesehatan disajikan padaTabel 1.

Tabel 1.1. Trend Perkembangan Jumlah Mahasiswa Fakultas Ilmu Kesehatan UNW Mataram

\begin{tabular}{ccccc}
\hline \multirow{2}{*}{ No. } & \multirow{2}{*}{ Tahun } & \multicolumn{2}{c}{ Jumlah Mahasiswa } & \multirow{2}{*}{ Jumlah } \\
\cline { 3 - 4 } 1 & 2016 & Laki & Perempuan & \\
\cline { 3 - 4 } 2 & 2017 & 57 & 120 & 200 \\
3 & 2018 & 32 & 83 & 150 \\
4 & 2019 & 20 & 63 & 112 \\
\multicolumn{3}{c}{ Total } & 83 \\
\cline { 3 - 4 } & & & 545 \\
\hline
\end{tabular}

Sumber: Wawancara Wakil Dekan III bagian Kemahasiswaan

Dengan adanya penurunan jumlah pendaftar, seharusnya pihak institusi melakukan pengkajian terhadap semua aspek salah satunyaialah loyalitas mahasiswa.Mahasiswa merupakan jalur penyambung antara institusi dengan masyarakat luas. Jika mahasiswa puas dengan pelayanan pendidikan yang ada, maka loyalitas mahasiswa menjadi meningkat dan setidaknya akan memberikan rekomendasi yang baik dan positif kepada masyarakat. Sehingga nilai institusi akan tinggi dan memberikan efek positif. Dengan demikian masyarakat percayaatas layanan pendidikan tersebut.

Layanan akademik yang diberikan olehperguruan tinggi merupakan salah satu ukuran dari keberhasilan lembaga pendidikan dalam mempertahankan produk jasa pendidikan(Manik, \&Sidharta, 2017).Kewajiban menjadikan staf pelayanan mampu memberikan pelayanan secara profesional kepada para konsumen juga merupakan tuntutan yang tidak mudah untuk dipenuhi, apabila lembaga tidak dengan segera merintisnya (Juandi 2018).

Institusi pendidikan Fakultas Ilmu Kesehatan Universitas Nahdlatul Wathan Mataram (FIK UNW) selalu bertekad untuk menjaga mutu pendidikan yang baik, ini terbukti dengan adanya tanggung jawab yayasan untuk memberikan fasilitas kepada semua dosen dan staf untuk melanjutkan pendidikan. Hal lain yang dilakukan yayasan adalah dengan memperbaiki fasilitas bangunanbaik itu berupa laboratorium, perpustakaan dan fasilitas yang lain. Tetapi dengan adanya beberapa perbaikan tersebuttidak menjadikanFIKUNW mataram sebagai institusi pendidikan yang banyak diminati calon mahasiswa, ini terbukti dengan adanya penurunan jumlah pendaftar mahasiswa baru hingga pada tahun akademik 2019/2020. Hal ini merupakan salah satu dampak rendahnya loyalitas mahasiswa terhadap FIK UNW Mataram. Berdasarkan wawancara dengan 15 mahasiswa didapatkan 10 mahasiswa yang tidak pernah merekomendasikan FIK UNW Mataram ke teman atau keluarga.

Hasil wawancara tersebut, sejalan dengan pernyataan Wakil Dekan FIK UNW Mataram yang menyatakan bahwamenurunnya pendaftar calon mahasiswamemberikan dampak yang 
signifikan terhadap beberapa aspek pendukung berjalannya administrasi pada proses pembelajaran. Penurunan minat konsumen terhadap suatu barang ini menandakan bahwa adanya ketidakpuasan terhadap barang atau jasa tersebut, atau kemugkinan barang atau jasa ditempat lain atau penjual lain lebih menarik.

Berdasarkan pemaparan diatas, peneliti tertarik untuk melakukan penelitian yang berjudul "Pengaruh Kualitas Layanan Akademik dan Kepuasan Mahasiswa terhadap Loyalitas Mahasiswa pada Fakultas Ilmu Kesehatan Universitas Nahdlatul Wathan Mataram". Sepanjang pengetahuan penulis, bahwa sampai saat ini belum ada peneliti yang meneliti terkait variabel penelitian ini yang dilakukan di FIK UNW Mataram.

\section{METODE PENELITIAN}

Penelitian ini menggunakan pendekatan kuantitatif (Arikunto, 2013). Penelitian ini merupakan penelitian ex-post facto dengan mengumpulkan data berupa angka-angka dan diolah menggunakan statistik program SPSS versi 16. Penelitian ex-post facto dalam penelitian ini karena ingin menemukan penyebab yang memungkinkan perubahan perilaku, gejala atau fenomena yang disebabkan oleh suatu peristiwa, perilaku atau hal-hal sebagai penyebab perubahan pada variabel bebas yang secara keseluruhan sudah terjadi. Rancangan penelitian seperti disajikan pada Gambar 1.

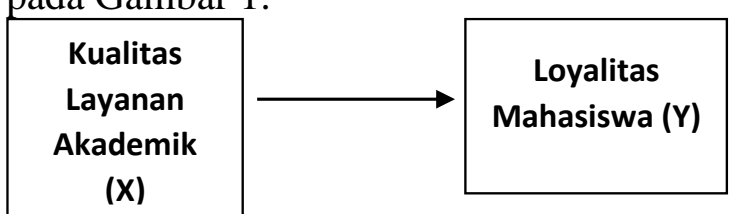

Gambar 1. Rancangan

Gambar 1. menjelaskan pengaruh kualitas layanan akademik (X) terhadap loyalitas mahasiswa (Y). Untuk mencari pengaruh $\mathrm{X}$ terhadap $\mathrm{Y}$ menggunakan regresi linier sederhana.

Populasi dalam penelitian ini adalah mahasiswa dari 3 jurusan di Fakultas Ilmu Kesehatan Universitas Nahdlatul Wathan
Mataram, yaitu: prodi keperawatan sejumlah 43 orang, prodi kebidanan sejumlah 31 orang dan prodi farmasi sejumlah 233 orang dengan total 307 orang mahasiswa.

Penentuan sampel menggunakan teknik purposive sampling. Berdasarkan pendapat Sugiyono (2013), adalah teknik penentuan sampel dengan pertimbangan tertentu. Pendapat Arikunto (2013), apabila subjeknya kurang dari 100, lebih baik diambil semua sehingga penelitiannya merupakan penelitian populasi. Selanjutnya, jika jumlah subjeknya besar dapat diambil antara 10-15\% atau 20-25\% atau lebih. Sampel yang digunakan dari penelitian ini berjumlah 40 sampel dengan rincian 6 sampel dari keperawatan, 4 sampel dari kebidanan dan 30 sampel dari farmasi.

Instrumen yang digunakan dalam penelitian ini adalah kuesioner dengan skala Likert. Teknik analisis data menggunakan uji linieritas, uji normalitas dan uji hipotesis.

\section{HASIL DAN PEMBAHASAN Loyalitas Mahasiswa}

Penelitian ini menggunakan 40 responden berasal dari Fakultas Ilmu Kesehatan Universitas Nahdlatul Wathan Mataram, kemudian diukur dengan 15 butir pernyataan menggunakan 4 pilihan jawaban, sehingga skor variabel ini antara 15 sampai 60, maka diperoleh hasil seperti Tabel 2 berikut:

Tabel 2. Hasil Analisis Deskriptif Loyalitas Mahasiswa

\begin{tabular}{|c|l|l|l|l|}
\hline \multirow{2}{*}{$\begin{array}{l}\text { Jumlah } \\
\text { Responden } \\
(\mathrm{N})\end{array}$} & \multicolumn{4}{|c|}{ Nilai } \\
\cline { 2 - 5 } & Minimal & Maximal & Mean & $\begin{array}{l}\text { Standar } \\
\text { Deviasi }\end{array}$ \\
\hline \multicolumn{1}{|c|}{40} & 48 & 95 & 76,98 & 11,086 \\
\hline
\end{tabular}

\section{Sumber: Output SPSS}

Berdasarkan Tabel 2 diperoleh nilai rata-rata loyalitas mahasiswa dengan nilai skor terendah 48, skor tertinggi 95, rerata skor 76,98, dan standar deviasi 11,086, bahwa terdapat mahasiswa dengan skor rendah 48. Hal ini menunjukkan perlu adanya perbaikan dari sisi loyalitas mahasiswa yang semestinya dilakukan FIK 
UNW Mataram guna meningkatkan loyalitas mahasiswa.Data tersebut dikelompokkan guna pembuatan frekuensi sesuai langkah yang disampaikan Riduwan (2014), agar dapat memberi informasi lebih rinci tentang loyalitas mahasiswa.

Langkah penyusunan distribusi frekuensi terdiri dari 7 (tujuh) langkah, yaitu: a) mengurutkan data dari kecil ke besar (ascending), b) menghitung jarak atau rentangan (R), c) menghitung jumlah kelas (K) menggunakan rumus Sturges: Jumlah Kelas $(K)=1+3.3 \log n$ ( $n=$ jumlah data), d) menghitung panjang kelas interval $(\mathrm{P})$, rumus: $P=\frac{\operatorname{Rentangan}(R)}{\text { JumlahKelas }(K)}$, e) menentukan batas data terendah, kemudian menghitung kelas interval dengan menjumlahkan ujung bawah kelas sampai pada data terakhir, f) membuat tabulasi data, g) membuat tabel distribusi frekuensi dengan cara memindahkah semua angka frekuensi (f). Hasilnya disajikan pada Tabel 3.

Tabel 3. Distribusi Loyalitas Mahasiswa

\begin{tabular}{c|c|c|c|}
\hline Kelas & Nilai Interval & Frekuensi & Presentase (\%) \\
\hline 1 & $48-55$ & 2 & 5,00 \\
\hline 2 & $56-63$ & 4 & 10,00 \\
\hline 3 & $64-71$ & 5 & 12,50 \\
\hline 4 & $72-79$ & 12 & 30,00 \\
\hline 5 & $80-87$ & 10 & 25,00 \\
\hline 6 & $88-95$ & 7 & 17,50 \\
\hline & Jumlah & 40 & 100,0 \\
\hline
\end{tabular}

Distribusi loyalitas mahasiswa yang telah dibuat kelas tersebut, dibuatkan kriteria yang disajikan pada Gambar 2.

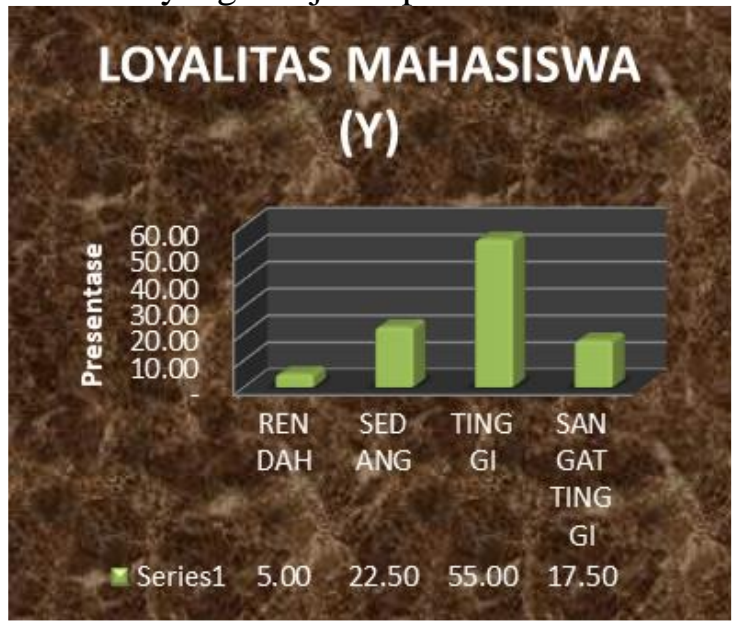

Gambar 2. Grafik Kategori Loyalitas Mahasiswa (Y)
Berdasarkan Tabel 3. dan Gambar 2 menunjukkan bahwa sebaran data loyalitas mahasiswa sebesar 55,00 \%, jika diasumsikan kelompok menjadi 4 kategori yaitu: kelas 1 adalah kelompok rendah, kelas 2 dan 3 adalah kelompok sedang, kelas 4 dan 5 adalah kelompok tinggi, dan kelas 6 adalah kelompok sangat tinggi, maka sebaran data loyalitas mahasiswa ini dikategorikan tinggi.

\section{Kualitas Layanan Akademik}

Menggunakan 40 responden berasal dari Fakultas Ilmu Kesehatan Universitas Nahdlatul Wathan Mataram, kemudian diukur dengan 18 butir pernyataan dengan 4 pilihan jawaban, sehingga skor variabel ini antara 18 sampai 72, maka diperoleh hasil seperti Tabel 4.

Tabel 4. Hasil Analisis Deskriptif Kualitas Layanan Akademik

\begin{tabular}{|c|l|l|l|l|}
\hline \multirow{2}{*}{$\begin{array}{l}\text { Jumlah } \\
\text { Responden } \\
(\mathrm{N})\end{array}$} & \multicolumn{4}{|c|}{ Nilai } \\
\cline { 2 - 5 } & Minimal & Maximal & Mean & $\begin{array}{l}\text { Standar } \\
\text { Deviasi }\end{array}$ \\
\hline 40 & 42 & 94 & 73,83 & 12,268 \\
\hline
\end{tabular}

Tabel 4 menunjukkan bahwa nilai rata-rata kualitas layanan akademik dengan nilai skor terendah 42 , skor tertinggi 94 , rerata skor 73,83 , dan standar deviasi 12,268 , bahwa terdapat mahasiswa dengan skor rendah 42 yang menunjukkan kualitas layanan akademik yang diberikan oleh FIK UNW Mataram kepada mahasiswa selama ini perlu ditingkatkan lagi, sehingga kualitas layanan akademik meningkat dan berimbas positif kepada mahasiswa. Selanjutnya, data yang telah diperoleh dibuatkan distribusi kualitas layanan akademik dan hasilnya disajikan pada Tabel 5.

Tabel 5. Distribusi Kualitas Layanan Akademik

\begin{tabular}{|c|c|c|c|}
\hline Kelas & Nilai Interval & Frekuensi & Presentase $(\%)$ \\
\hline 1 & $42-50$ & 2 & 5,00 \\
\hline 2 & $51-59$ & 3 & 7,50 \\
\hline 3 & $60-77$ & 6 & 15,00 \\
\hline 4 & $69-83$ & 11 & 27,00 \\
\hline 5 & $78-89$ & 13 & 32,50 \\
\hline 6 & $87-95$ & 5 & 12,50 \\
\hline & Jumlah & 40 & 100,00 \\
\hline
\end{tabular}

Distribusi kualitas layanan akademik yang telah tersusun kelas tersebut, dibuatkan kriteria seperti Gambar 3. 


\section{KUALITAS LAYANAN AKADEMIK (X)}

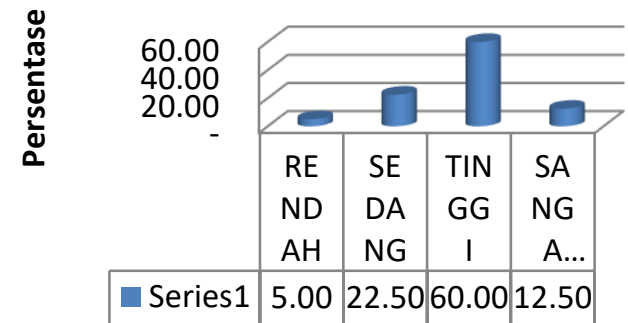

Gambar 3. Grafik Kategori Kualitas Layanan Akademik (X)

Berdasarkan Tabel 5. dan Gambar 3 diperoleh bahwa sebaran data kualitas layanan akademik sebesar $60 \%$, jika diasumsikan kelompok menjadi 4 kategori, yaitu: kelas 1 adalah kelompok rendah, kelas 2 dan 3 adalah kelompok sedang, kelas 4 dan 5 adalah kelompok tinggi, dan kelas 6 adalah kelompok sangat tinggi, maka sebaran data kualitas layanan akademik ini dikategorikan tinggi.

Berdasarkan uji hipotesis yang dilakukan, ada pengaruh kualitas layanan akademik terhadap loyalitas mahasiswa pada Fakultas Ilmu Kesehatan Universitas Nahdlatul Wathan Mataram. Hasil analisis regresi linier sederhana menggunakan SPSS disajikan pada tabel 7.

Tabel 7. Hasil Analisis Pengaruh Kualitas Layanan Akademik Terhadap Loyalitas Mahasiswa Pada Fakultas Ilmu Kesehatan Universitas Nahdlatul Wathan Mataram

\begin{tabular}{|c|c|c|c|c|}
\hline \multirow[b]{2}{*}{ Model } & \multicolumn{2}{|c|}{ Koefisien } & \multirow[b]{2}{*}{$\mathrm{t}$ hitung } & \multirow[b]{2}{*}{ Sig. } \\
\hline & B & $\begin{array}{c}\text { Standar } \\
\text { Kesalahan }\end{array}$ & & \\
\hline Konstan & 29,222 & 7,658 & 3,816 & 0,000 \\
\hline $\begin{array}{l}\text { Kualitas layanan } \\
\text { akademik }\end{array}$ & 0,647 & 0,102 & 6,319 & 0,000 \\
\hline
\end{tabular}

Sumber : Hasil Pengolahan Data dengan SPSS

Tabel 7 termuat nilai thitung sebesar 6,319 lebih besar dari nilai tabel sebesar 4,10 yang diperoleh dari jumlah responden dikurangi jumlah variabel, berarti 38 dengan taraf siginifikansi 0,05. Disimpulkan bahwa ada pengaruh kualitas layanan akademik terhadap loyalitas mahasiswa pada Fakultas Ilmu Kesehatan Universitas Nahdlatul Wathan Mataram.

Selanjutnya, hasil analisis diperoleh koefisien regresi kualitas layanan akademik sebesar 0,647, konstanta (intercept) sebesar 29,222, dan bentuk persamaan regresi $X$ terhadap $\mathrm{Y}$ adalah $\hat{\mathrm{Y}}=29,222+0,647 \mathrm{X}$, berarti perubahan satu unit variabel kualitas layanan akademik diikuti oleh variabel loyalitas mahasiswa pada Fakultas Ilmu Kesehatan Universitas Nahdlatul Wathan Mataram sebesar 0,647 unit pada arah yang sama dengan intercept sebesar 29,222. Grafik persamaan regresi disajikan pada Gambar 4.

\section{Grafik Secara Parsial Kualitas Layanan Akademik (X)}

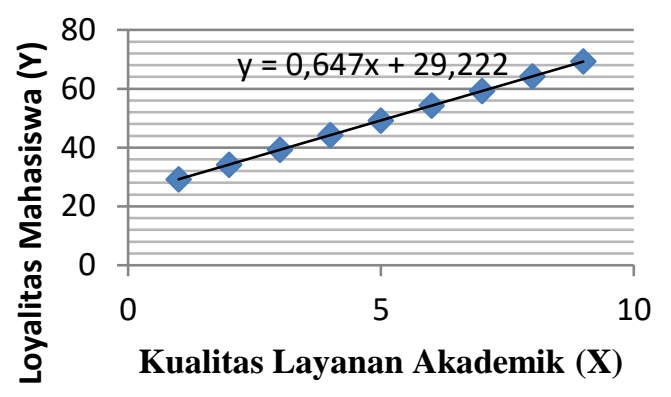

Gambar 4. Grafik Pengaruh Kualitas Layanan Akademik terhadap Loyalitas Mahasiswa pada Fakultas Ilmu Kesehatan Universitas Nahdlatul Wathan Mataram

Besarnya pengaruh kualitas layanan akademik terhadap loyalitas mahasiswa pada Fakultas Ilmu Kesehatan Universitas Nahdlatul Wathan Mataram dapat dilihatdari koefisien $\mathrm{R}^{2}$ Terkoreksi, disajikan seperti pada Tabel 8.

Tabel 8 Hasil Analisis Besarnya Pengaruh Kualitas layanan akademik terhadap Loyalitas mahasiswa pada Fakultas Ilmu Kesehatan Universitas Nahdlatul Wathan Mataram

\begin{tabular}{|l|c|c|c|c|}
\hline \multirow{2}{*}{ Uraian } & \multicolumn{2}{|c|}{ Nilai } & \multirow{2}{*}{ F } & Sig. \\
\cline { 2 - 3 } & $\mathrm{R}$ & $\begin{array}{c}\mathrm{R}^{2} \\
\text { Terkoreksi }\end{array}$ & & (2) \\
\hline $\begin{array}{l}\text { Kualitas layanan } \\
\text { akademik terhadap } \\
\text { Loyalitas mahasiswa }\end{array}$ & 0,716 & 0,500 & 39,934 & 0,000 \\
\hline
\end{tabular}




\section{Sumber : Hasil Pengolahan Data SPSS}

Berdasrkan Tabel 8 diperoleh bahwa Koefisien $\mathrm{R}^{2}$ Terkoreksi sebesar 0,500, artinya kualitas layanan akademik memiliki pengaruh sebesar 50,0\% terhadap loyalitas mahasiswa pada Fakultas Ilmu Kesehatan Universitas Nahdlatul Wathan Mataram.

Adanya pengaruh kualitas layanan akademik terhadap loyalitas mahasiswa sebesar $50 \%$, menunjukkan bahwa layanan akademik pada Fakultas Ilmu Kesehatan Universitas Nahdlatul Wathan Mataram telah dapat mempengaruhi loyalitas dari mahasiswa untuk terus melaksanakan perkuliahan di FIK UNW Mataram. Persentase pengaruh terbilang sedang ini, perlu menjadi perhatian pihak kampus untuk dapat mencari solusi dikemudian hari, agar kontribusi kualitas layanan akademik ini memiliki sumbangan lebih besar, sehingga layanan yang baik akan menjadikan puasnya mahasiswa dalam melaksanakan perkuliahan di FIK UNW Mataram.

Hal ini sejalan dengan Penelitian ini sesuai dengan penelitian yang telah dilakukan oleh Indirwan (2016), bahwa memberikan layanan kepada mahasiswa merupakan tuntutan mutlak diperlukan agar tercipta suatu loyalitas bagi staf kepegawaian untuk mencintai pekerjaan dan memberikan dedikasi yang tinggi terhadap pekerjaannya. Oleh karena itu, diperlukan konsep berwawasan luas demi memusatkan perhatian pada pelayanan dan kebutuhan mahasiswa.Hal ini dibutuhkan untuk meningkatkan loyalitas mahasiswa dengan meningkatnya kinerja pegawai maka meningkatkan kepuasan semua pihak dan sejalan dengan itu meningkat pula loyalitas mahasiswa untuk tetap menuntaskan perkuliahan.

Hasil kualitas layanan yang baik dalam peningkatan kepuasan mahasiswa dan mengarah pada keuntungan jangka panjang dalam pangsa pasar dan profitabilitas (Anderson, et al., 1994).Saat ini, persaingan pendidikan tinggi semakin ketat tidak hanya untuk pasar lokal tetapi juga internasional.Untuk mencapai pangsa pasar yang besar, loyalitas mahasiswa perlu dimaksimalkan dan salah satu strateginya adalah dengan memberikan layanan yang berkualitas (Stevens, et al., 1995).

Layanan akademik merupakan salah satu faktor eksternal. Di sisi lain, layanan tersebut banyak berkaitan langsung dengan mahasiswa, sehingga perguruan tinggi dalam memenuhi layanan akademik harus berusaha memahami dan memenuhi kebutuhan mahasiswa dengan membangun persepsi kepuasan mahasiswa. Seperti yang dijelaskan oleh Taman, et al., (2013) bahwa upaya meningkatkan kualitas layanan akademik dengan mengarah pada kepuasan mahasiswa akan meningkatkan hasil belajar mahasiswa.

Konsep kualitas layanan dan kepuasan saling berhubungan satu sama lain. Secara teoritis dalam proses tersebut dapat memberikan acuan dalam penelitian ini, dimana kualitasnyalayanan mempengaruhi loyalitas mahasiswa. Terciptanya kepuasan mahasiswa bisa memberikan beberapamanfaat, diantaranya hubungan perguruan tinggi dan mahasiswa menjadi harmonis, memberikan landasan yang baik bagi perguruan tinggi dalam meningkatkan citranya (Tjiptono \& Chandra, 2008).

Hasil penelitian Martínez-Argüelles \& Batalla-Busquets (2016) menyatakan bahwa variabel kualitas pelayananberpengaruh langsung positif dan signifikan terhadap loyalitas mahasiswa di Perguruan Tinggi. Hal ini memberikan makna bahwa kualitas pelayanan yang baik akan berdampak pada peningkatan mahasiswaloyalitas mahasiswa. Hal ini menunjukkan tersedianya jumlah ruang kuliah yang cukup nyaman.

Hal lain juga yang mempengaruhi loyalitas mahasiswa ialah kemampuan dosen dalam menyampaikan materi sudah cukup baik, respon karyawan dalam memberikan pelayanan (Noviasari, et al., 2015). Saat dibutuhkan layanan akademik akanmembantu mahasiswa yang kesulitan dengan cepat. Dosen memiliki banyak pengalaman mengajardan lulus dari universitas terkemuka, dan bagian 
akademik memberikan layanan tanpa membedakanmahasiswa dalam memberikan layanan admistrasi yang dibutuhkan.

Hasil penelitian ini sama dengan penelitian Yuliawan (2017) yang menunjukkan kualitaspelayanan administrasi akademik berpengaruh positif dan signifikan terhadap kepuasan dan loyalitas mahasiswa.

Hasil penelitian lain juga memperkuat hasil penelitian yang dilakukan oleh Ghozali (2010), Noviasari dkk(2015), Mekic \& Mekic (2016), Chandra, et al., (2018), Dora (2017), Jiewanto, et al., (2012), Lunarindiah(2016) dan Ratnasari (2016) kualitas pelayanan berpengaruh terhadap loyalitas mahasiswa. Asaduzzaman, et al., (2013) menyatakan bahwa terdapat hubungan yang signifikan antara konstruk kualitas pelayanan dengan loyalitas mahasiswa.

Kualitas layanan sangat penting dalam pendidikan tinggi (O'Neill dan Palmer, 2004; Parri, 2006; Quinn et al., 2009).

Mahasiswa lebih memilih perguruan tinggi yang memberikan kualitas pelayanan dan kepuasan mahasiswa yang lebih baik (Tahir, Bakar, \& Ismail, 2010) yang baik secara langsung maupun tidak langsung mempengaruhi loyalitas mahasiswa (Annamdevula \& Bellamkonda, 2016). Ketika mahasiswa loyal, mereka akan setia pada institusi yang dipilih dan akan mempromosikan kampus tersebut kepada para kerabatnya (Alves \& Raposo, 2009). Penelitian yang dilakukan di India oleh (Annamdevula \& Bellamkonda, 2016) menemukan hubungan positif antara kualitas layanan dan kepuasan mahasiswa, kualitas layanan dengan loyalitas mahasiswa, dan kepuasan mahasiswa dengan loyalitas mahasiswa.Hal ini juga didukung oleh penelitian yang dilakukan oleh Duarte, et al., (2012)terdapat hubungan antara kualitas mahasiswa dan loyalitas mahasiswa.

Rinala, et al., (2013) menyatakan bahwa kualitas layanan akademik berpengaruh signifikan terhadap loyalitas mahasiswa melalui kepuasan mahasiswa. Loyalitas mahasiswa dalam penelitian ini terkait loyalitas mahasiswa menyelesaikan studi, keinginan mahasiswa untuk melanjutkan studi pada universitas yang sama dan memberikan rekomendasi, memberikan info tentang keberadaan FIK UNW Mataram kepada orang lain.

Adanya layanan akademik yang berkualitas mampu memberikan rasa kepuasan terhadap penggunanya dalam hal ini mahasiswa. Jika kepuasan sudah didapat maka loyalitas seseorang akan meningkat terhadap suatu jasa. Begitu pula dengan mahasiswa akan memiliki loyalitas yang tinggi terhadap instasi pendidikan tempat mereka belajar, sehingga dengan mudah mereka memberikan rekomendasi kepada setiap orang yang akan menggunakan instansi pendidikan tersebut. Pengaruh seperti ini sangat bermanfaat terhadap mutu pendidikan itu sendiri. Adanya loyalitas mahasiswa yang tinggi, akan sangat menguntungkan bagi institusi pendidikan. Ketika loyalitas tinggi maka minat seseorang akan tinggi juga, sehingga mutu pendidikan akan menjadi baik pula.

Artinya setiap peningkatan layanan akademik akanberpengaruh terhadap loyalitas mahasiswa. Namun temuan ini berbeda dengan temuan penelitian Karami (2012). Penelitian Karami -dilakukan terhadap 223 siswa perdagangan di Selandia Baru - menunjukkan bahwa harga yang dipersepsikan siswa tidak memilikiberdampak pada loyalitas siswa.

Perbedaan ini mungkin disebabkan oleh beberapa alasan.Pertama, penelitian ini adalahdilakukan di negara berkembang. Sedangkan penelitian Kao dilakukan di negara maju. Bagi negara maju, biaya pendidikan bukanlah masalah besar bagi mereka dibandingkan dengan negara berkembang.

Hal ini membuat siswa di negara berkembang lebih memperhatikan biaya pendidikan.Kedua, menurut Karami (2012), siswa yang menjadi objek studinya tidak membayar sendiri atau membayar SPP sendiridibayar dalam porsi tertentu, sehingga mereka kurang peka terhadap hal 
ini. Konteks yang berbeda diterapkan untuk inipenelitian, dari mana mereka berasal dari universitas negeri. Di Indonesia, ada kecenderungan perguruan tinggi negerisiswa membayar biaya sekolah mereka sendiri, baik melalui pekerjaan paruh waktu, beasiswa, atau oleh penenun uang sekolah.

\section{KESIMPULAN}

Ada pengaruh kualitas layanan akademik $(\mathrm{X})$ terhadap loyalitas mahasiswa (Y) pada Fakultas Ilmu Kesehatan Universitas Nahdlatul Wathan Mataram sebesar $50 \%$.Kontribusi ini dapat ditingkatkan lagi oleh FIK UNW Mataram dengan memperhatikan tingkat kepuasan mahasiswa agar sejalan dengan peningkatan loyalitas mahasiswa.Sehingga kualitas layanan akademik yang mencakup kualitas pembelajaran, bimbingan akademik, komunikasi dengan pimpinan/staff universitas, dan pelayanan administrasi dapat lebih dioptimalkan, sehingga dirasakan langsung oleh mahasiswa Fakultas Ilmu Kesehatan Universitas Nahdlatul Wathan Mataram.

\section{SARAN}

Hasil penelitian ini dapat dijadikan salah satu masukan dan pertimbangan bagi pihak Fakultas Ilmu Kesehatan Universitas Nahdlatul Wathan Mataram dalam meningkatkan kualitas layanan akademik guna menanamkan loyalitas mahasiswa untuk terus dapat menuntaskan pendidikannya sekaligus sebagai sarana promosi secara langsung dan tidak langsung di tengah masyarakat berdasarkan informasi dari mulut ke mulut yang dilakukan oleh mahasiswa FIK UNW Mataram.

\section{DAFTAR PUSTAKA}

Abdullah, F. (2006). The development of HEdPERF: a new measuring instrument of service quality for the higher education sector. International journal of consumer studies, 30(6), 569581.
Anderson, E. W., Fornell, C., \& Lehmann, D. R. (1994). Customer satisfaction, market share, and profitability: Findings from Sweden. Journal of marketing, 58(3), 53-66.

Annamdevula, S., \& Bellamkonda, R. S. (2016). Effect of student perceived service quality on student satisfaction, loyalty and motivation in Indian universities. Journal of Modelling in Management.

Appuhamilage, K. S. M., \& Torii, H. (2019). The impact of loyalty on the student satisfaction in higher education. Higher Education Evaluation and Development.

Arikunto, S. (2013). Prosedur penelitian atau pendekatan praktik. Cet XV.

Fares, D., \& Kachkar, O. (2013). The impact of service quality, student satisfaction, and university reputation on student loyalty: A case study of international students in IIUM, Malaysia. Information Management and Business Review, 5(12), 584590.

Ghozali, I. (2010). Analisis Kualitas Jasa Pendidikan dan Pengaruhnya Terhadap Loyalitas Mahasiswa Pada Perguruan Tinggi Swasta (PTS) Di Kota Semarang. Jurnal Media Ekonomi dan Manajemen, 21(1), 89-101.

Gunawan, A., \& Wahyuni, S. F. (2018). The Effect of Marketing Mix, Service Quality, Islamic Values and Institutional Image on Students' Satisfaction and Loyalty. Expert Journal of Marketing, 6(2).

Indirwan, I. (2016). Persepsi Mahasiswa terhadap Kualitas Pelayanan Akademik Pascasarjana UIN Alauddin Makassar (Doctoral dissertation, Universitas Islam Negeri Alauddin Makassar).

Ismanova, D. (2019). Students' loyalty in higher education: The mediating effect of satisfaction, trust, commitment on student loyalty 
to Alma Mater. Management Science Letters, 9(8), 11611168.

Juandi, I. (2018). Pengaruh Kualitas Layanan terhadap Kepuasan Mahasiswa dan Loyalitas Mahasiswa di Sekolah Tinggi Teknologi Jawa Barat. Jurnal Soshum Insentif, 136-152.

Karami, M., \& Olfati, O. (2012). Measuring service quality and satisfaction of students: A case study of students perception of service quality in high-ranking business schools in Iran. African Journal of Business Management, 6(2), 658-669.

Kotler, P., \& Keller, K. L. (2015). Marketing management, global edition. Pearson Education UK.

Manik, E., \&Sidharta, I. (2017). The impact of academic service quality on student satisfaction.

Martínez-Argüelles, M. J., \& BatallaBusquets, J. M. (2016). Perceived service quality and student loyalty in an online university. International Review of Research in Open and Distributed Learning, 17(4), 264-279.

Mekić, E., \& Mekić, E. (2016, April). Impact of higher education service quality on student satisfaction and its influence on loyalty: focus on first cycle of studies at accredited heis in BH. In International Conference on Economic and Social Studies (ICESoS'16)-Proceedings Book (pp. 43-56).

Noviasari, R. A., Wulandari, D., \& Suryaningsih, I. B. (2015). Pengaruh Citra Institusi dan Kualitas Layanan Terhadap Kepuasan dan Loyalitas Mahasiswa Universitas Moch. Sroedji Jember. BISMA: Jurnal Bisnis dan Manajemen, 9(2), 190-201.
O’Neill, M.A. and Palmer, A. (2004), "Importance-performance

analysis: a useful tool for directing continuous quality improvement in higher education", Quality Assurance in Education, Vol. 12 No. 1, pp. 3952.

Parri, J. (2006), "Quality in higher education", Vadyba/Management, Vol. 2 No. 11, pp. 107-111

Quinn, A., Lemay, G., Larsen, P. and Johnson, D.M. (2009), "Service quality in higher education", Total Quality Management, Vol. 20 No. 2, pp. 139-152.

Rinala, I. N., Yudana, I. M., \& Natajaya, I. N. (2013). Pengaruh kualitas pelayanan akademik terhadap kepuasan dan loyalitas mahasiswa pada Sekolah Tinggi Pariwisata Nusa Dua Bali. Jurnal Administrasi Pendidikan Indonesia, 4(1).

Stevens, P., Knutson, B., \& Patton, M. (1995). DINESERV: A tool for measuring service quality in restaurants. The Cornell Hotel and Restaurant Administration Quarterly, 36(2), 5-60.

Sugiyono. (2013). Metode Penelitian Kuantitatif, Kualitatif Dan R\&D. Bandung: Alfabeta.

Tahir, I. M., Bakar, N. M. A., \& Ismail, W. Z. W. (2010). Importanceperformance analysis of service quality among business students: An exploratory study. Interdiciplinary Journal of Contempory Research of Business, 2(1), 330-341.

Taman, A., Sukirno, S., Sari, A. R., Setiawan, N., \& Pustikaningsih, A. (2013). Analisis Kualitas Pelayanan Terhadap Kepuasan Mahasiswa Pada Fakultas Ekonomi Universitas Negeri Yogyakarta. Nominal: Barometer Riset Akuntansi dan Manajemen, 2(1), 99-111. 
Tjiptono, F., \& Chandra, G. (2016). Service, Quality dan Satisfaction, Yogya: Penerbit

Yuliawan, R. (2017). Pengaruh kualitas pelayanan pegawai administrasi akademik terhadap kepuasan mahasiswa. Eksis: Jurnal Riset Ekonomi dan Bisnis, 12(2), 126134. 